Note

\section{Some Properties of Starch from Foxtail Millet (Setaria italica BEAUV.)}

\author{
Shuzo Fuitta, ${ }^{\dagger}$ Li Donghui, ${ }^{*}$ \\ Yoshimi Sugmoto, ${ }^{* *}$ Naoyoshi INOuCHI ${ }^{* * *}$ \\ and Hidetsugu FUWA**** \\ Division of Food, Mie Municipal College, \\ Isshinden, Tsu-shi, Mie 514-01, Japan \\ *Foxtail Millet Research Institute, \\ Academy of Agricultural and Forestry Science, \\ Hebei Province, China \\ **Department of Home Science, Mukogawa Women's \\ University, Nishinomiya, Hyogo 663, Japan \\ ***Division of Food, Sakurai Women's College, \\ Sakurai, Nara 630, Japan \\ ****Department of Food and Nutrition, \\ Osaka City University, Osaka 558, Japan
}

Received October 17, 1988

Foxtail millet (or italian millet, Setaria italica BEAUv.) has been extensively cultivated in Eurasia as food and forage. ${ }^{1 \sim 4)}$ In Japan today, millet is only consumed as a sweetstuff such as "Awa-okoshi" and a millet cake called "Awa-mochi," or as birdseed. In China, however, it has been widely used for more than 2,000 years as nutritional gruel or soup for pregnant and nursing women, and has recently been applied to food therapy. ${ }^{5}$ )

The main component of this millet is starch and protein. ${ }^{6)}$ Two types of foxtail millet starch have been recognized, namely the waxy and non-waxytypes. Taira investigated the amylose content of millet starches, ${ }^{7)}$ and Lorenz reported that the amylographic viscosity of foxtail and proso millet starches was higher than that of rye and wheat starches. ${ }^{8}$ However, many more details still remain to be clarified. In the present study, we examined the structure and properties of foxtail millet starches to reveal the detail characteristics of starches obtained from seveal varieties of this millet.

Thirteen different varieties of foxtail millet cultivated in China were examined (see Table I). They were either typical representatives of varieties cultivated in China or those having special characteristics. The YOUZHI group has superior qualities; for example, YOUZHI- 1 and -4 show higher contents of protein, each having 16.2 and $17.4 \%$, respectively. JIQU was produced by irradiating of ${ }^{60} \mathrm{Co}$ and has an improved protein quality, while SHUQU and GAOLIANGQU were produced by crossing with proso millet and sorghum, respectively. Starch granules were prepared by the slightly modified method of Adkins and Greenwood, ${ }^{97}$ and were refluxed by $85 \%$ methanol for defatting. The absorption spectrum of starch-iodine complexes was measured by scanning from 700 to $500 \mathrm{~nm} .{ }^{10)}$ For fractionation of the debranched materials, starch was hydrolyzed with crystalline Pseudomonas isoamylase by the method of Ikawa ${ }^{11}$ and the materials were fractionated by gel filtration on a Sephadex G-75 column. The starch granules and distilled water $(1: 2$ by weight $)$ were sealed in an aluminum pan for thermographic analysis, the thermogram being measured on a Rigaku Denki 8240 differential scanning calorimeter (DSC) with water as the reference. ${ }^{12)}$

Table I shows the wavelength at the maximum absorbance of the iodine absorption spectrum $\left(A_{\max }\right)$ and the "blue value" (BV) at $680 \mathrm{~nm} . A_{\max }$ value for YOUZHI-2 and -4 were 535 and $536 \mathrm{~nm}$, respectively, and were in the range of 587 to $606 \mathrm{~nm}$ for the others. The BVs for the non-waxytypes were in the wide range of 0.340 to 0.518 , GAOLIANGQU, the foxtail millet-sorghum hybrid, showing the lowest $\mathrm{BV}$ among the non-waxytypes. Ikawa reported that the $\mathrm{BV}$ of sorghum starch was in the range of 0.20 to $0.34^{13)}$; therefore, the result suggests that GAOLIANGQU starch may be affected by the sorghum background. JIQU starch may be a high amylose type because its BV was 0.518 .

From gel filtration of the debranched materials on a Sephadex, the amylose content and distribution of the linear $\alpha-1,4$ chains of amylopectin are shown in Table I. The YOUZHI-2 and -4 starches, presumed to be the waxytype from their iodine absorption curves, contained 1.3 and $2.7 \%$ of fraction 1 (i.e., the amylose fraction), respectively, and approximately $3 \%$ of the carbohydrates were eluted in the intermediate fraction of both the millets. Taira reported that the varieties of the waxytype of foxtail millet could be divided into two groups by their amylose content (i.e., 0.82 and $4.20 \%$ groups on the average)..$^{7}$ The ratio of fraction 2 to 3 of YOUZHI-2 was as high as 4.1, and similar figures have also been observed for starches of adlay ${ }^{14)}$ and dull mutant of corn. ${ }^{11)}$ In the non-waxytype of millet, fraction 1 contents were in the range of 17.4 (LUMIQING) and $24.0 \%$ (JIQU). LUMIQING endosperm contains oligosaccharides, and therefore its soup or gruel has a sweet taste. The ratio of fraction 2 to 3 of the non-waxytype of starches was in the range of 2.6 to 3.5 .

From the DSC characteristics and pasting characteristics by DSC, SHUQU, the foxtail millet-proso millet hybrid, showed the lowest temperatures for gelatinization among the examined samples (Table II), the onset (To), peak (Tp) and conclusion (Tc) temperatures for gelatinization being higher than those of wheat and rye starches. ${ }^{8}$ JIQU, GAOLIANGQU and two waxytype millets (YOUZHI-2 and -4) showed higher temperatures for gelatinization. A waxytype of starch has, in general, a

\footnotetext{
$\dagger$ To whom inquiries should be addressed.
} 
Table I. Iodine Absorption Spectra and Gel Filtration of Starches from Foxtall Millet

\begin{tabular}{|c|c|c|c|c|c|c|c|c|c|c|}
\hline \multirow{3}{*}{ No. } & \multirow{3}{*}{ Sample name } & \multicolumn{4}{|c|}{ lodine absorption spectra } & \multicolumn{5}{|c|}{ Gel filtration of debranched materials ${ }^{a}$} \\
\hline & & \multicolumn{2}{|c|}{$A_{\max }$} & \multirow{2}{*}{ Type } & \multirow{2}{*}{$\begin{array}{c}\text { Blue value } \\
\text { (OD at } 680 \mathrm{~nm})\end{array}$} & \multirow{2}{*}{$\begin{array}{c}\text { Fraction } 1 \\
(\%)\end{array}$} & \multirow{2}{*}{$\begin{array}{l}\text { Intermediate } \\
\text { fraction }(\%)\end{array}$} & \multirow{2}{*}{$\begin{array}{c}\text { Fraction } 2 \\
(\%)\end{array}$} & \multirow{2}{*}{$\begin{array}{c}\text { Fraction } 3 \\
(\%)\end{array}$} & \multirow{2}{*}{ Fr.3/Fr.2 } \\
\hline & & $(\mathrm{nm})$ & $(\mathrm{OD})$ & & & & & & & \\
\hline 101 & YOUZHI 1 & 592 & 0.521 & Non-waxy & 0.414 & 20.8 & 7.8 & 18.7 & 52.7 & 2.8 \\
\hline 102 & YOUZHI 2 & 535 & 0.279 & Waxy & 0.094 & 1.3 & 3.1 & 18.7 & 76.8 & 4.1 \\
\hline 103 & YOUZHI 3 & 593 & 0.533 & Non-waxy & 0.427 & 21.0 & 5.6 & 17.5 & 55.9 & 3.2 \\
\hline 104 & YOUZHI 4 & 536 & 0.349 & Waxy & 0.130 & 2.7 & 3.5 & 23.3 & 70.6 & 3.0 \\
\hline 105 & JIQU 9 & 590 & 0.656 & Non-waxy & 0.518 & 24.0 & 4.4 & 18.6 & 52.9 & 2.8 \\
\hline 106 & LONGQU 23 & 595 & 0.517 & Non-waxy & 0.416 & 18.2 & 4.9 & 21.7 & 55.2 & 2.6 \\
\hline 107 & LONGQU 25 & 606 & 0.524 & Non-waxy & 0.456 & 22.2 & 5.5 & 17.8 & 54.5 & 3.1 \\
\hline 108 & NINGHUANG 1 & 590 & 0.559 & Non-waxy & 0.434 & 21.0 & 5.8 & 16.6 & 56.6 & 3.4 \\
\hline 109 & SHUQU & 598 & 0.554 & Non-waxy & 0.458 & 23.1 & 4.9 & 16.0 & 56.0 & 3.5 \\
\hline 110 & LUMIQING & 591 & 0.471 & Non-waxy & 0.372 & 17.4 & 4.8 & 19.3 & 59.3 & 3.1 \\
\hline 111 & CHANGLIBAIMI & 594 & 0.444 & Non-waxy & 0.354 & 18.3 & 3.5 & 19.1 & 59.0 & 3.1 \\
\hline 112 & GAOLIANQU & 594 & 0.430 & Non-waxy & 0.340 & 22.4 & 3.9 & 18.8 & 54.9 & 2.9 \\
\hline 113 & HEISHATAN & 587 & 0.475 & Non-waxy & 0.364 & 19.4 & 2.9 & 21.2 & 56.5 & 2.7 \\
\hline
\end{tabular}

a The range for fractions 1,2 and 3, and the intermediate fraction was divided according to the wavelength at maximum absorption ( $A_{\text {max }}$ ) of iodine-carbohydrate complexes as follows: Fraction $1, \Lambda_{\max } \geqq 620 \mathrm{~nm}$; intermediate fraction, $620>\Lambda_{\max } \geqq 600 \mathrm{~nm}$; fraction $2,600>\Lambda_{\max } \geqq 540 \mathrm{~nm}$; and fraction $3, A_{\max }<540 \mathrm{~nm}$. 


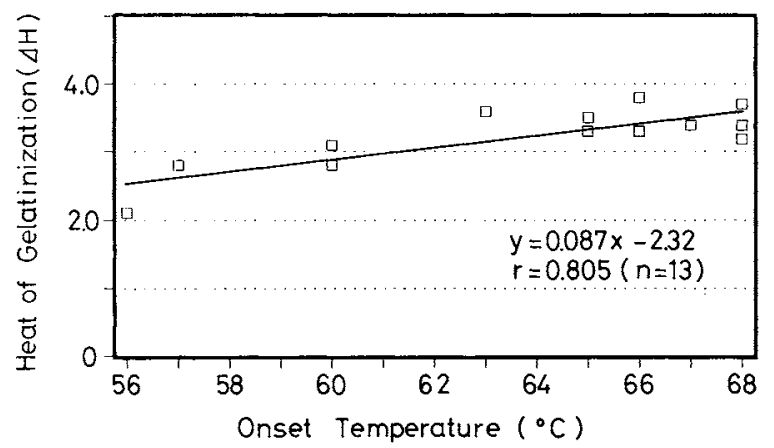

Fig. 1. Relationship between the Heat of Gelatinization and Onset Temperature for Gelatinization for Endosperm Starches of Foxtail Millet.

Table II. Characteristics of Starches of Foxtail Millet

\begin{tabular}{|c|c|c|c|c|c|}
\hline \multirow{2}{*}{ No. } & \multirow{2}{*}{ Sample name } & \multicolumn{3}{|c|}{$\begin{array}{l}\text { Temperature for } \\
\text { gelatinization }\end{array}$} & \multirow{2}{*}{$\begin{array}{c}\Delta H^{a} \\
(\mathrm{cal} / \mathrm{g})\end{array}$} \\
\hline & & $\begin{array}{l}\mathrm{To}^{a} \\
\left({ }^{\circ} \mathrm{C}\right)\end{array}$ & $\begin{array}{c}\mathrm{Tp} \\
\left({ }^{\circ} \mathrm{C}\right)\end{array}$ & $\begin{array}{c}\mathrm{Tc} \\
\left({ }^{\circ} \mathrm{C}\right)\end{array}$ & \\
\hline 101 & YOUZHI 1 & 65 & 72 & 79 & 3.5 \\
\hline 102 & YOUZHI 2 & 68 & 75 & 83 & 3.7 \\
\hline 103 & YOUZHI 3 & 67 & 74 & 81 & 3.4 \\
\hline 104 & YOUZHI 4 & 66 & 74 & 82 & 3.8 \\
\hline 105 & JIQU 9 & 68 & 74 & 81 & 3.2 \\
\hline 106 & LONGQU 23 & 60 & 66 & 74 & 3.1 \\
\hline 107 & LONGQU 25 & 60 & 67 & 74 & 2.8 \\
\hline 108 & NINGHUANG 1 & 66 & 73 & 79 & 3.3 \\
\hline 109 & SHUQU & 56 & 64 & 72 & 2.1 \\
\hline 110 & LUMIQING & 63 & 70 & 78 & 3.6 \\
\hline 111 & CHANGLIBAIMI & 57 & 65 & 75 & 2.8 \\
\hline 112 & GAOLIANGQU & 68 & 74 & 81 & 3.4 \\
\hline 113 & HEISHATAN & 65 & 71 & 77 & 3.3 \\
\hline
\end{tabular}

${ }^{a}$ Onset (To), peak (Tp) and conclusion (Te) temperatures for gelatinization, and the heat of gelatinization $(\Delta H)$ were measured.

higher temperature for gelatinization than the nonwaxytype, and a similar tendency has also been observed in other cereals. Lorenz has reported that the To values for two foxtail millet starches were 52 and $55^{\circ} \mathrm{C}$, respectively, ${ }^{8)}$ these figures being lower than the results obtained in this study. The difference in the result might have been due to the difference in the analytical methods and/or variety of millet. The heat of gelatinization $(\Delta H)$ of the non-waxytype averaged $3.1 \mathrm{cal} / \mathrm{g}$, SHUQU showing the smallest $\Delta H$ value $(2.1 \mathrm{cal} / \mathrm{g})$ of all. On the other hand, $\Delta H$ of the waxytype was $3.7 \mathrm{cal} / \mathrm{g}$ or more, greater than the values for the non-waxytype. A similar tendency has also been observed in $\operatorname{corn}^{12)}$ and rice. ${ }^{15 \text { ) }}$

Figure 1 shows the relationship between To and $\Delta H$ of the foxtail millet starches, a strong correlation being observed. The coefficient of correlation was 0.805 , but this relationship is not necessarily observed in other grains. A similar relationship has been found in $\operatorname{corn}^{12)}$ and rice, ${ }^{15 \sim 17)}$ but not clearly in adlay $^{14)}$ and sorghum starches. ${ }^{13)}$

\section{References}

1) S. Nakao, "Nature-Ecological Studies". (in Japanese), Chuokoronsha, Tokyo, 1967, pp. 32 494 .

2) J. M. J. de Wet, L. L. Oestray-Stidd and J. I. Cubero, J. d'Agric. Trad. et de Bota. Appl., 26, 53 (1979).

3) S. Sakamoto, J. Jpn. Soc. Starch Sci., 29, 41 (1982).

4) S. Sakamoto and T. Umesao, Gekkan Minpaku, 12, 2 (1988).

5) T. Li, Report of Foxtail Millet Research Institute, 1, 1 (1987).

6) T. Ohara, "Millets" (in Japanese), Jusonbo, Tokyo, 1981, pp. $20 \sim 36$.

7) H. Taira and T. Miyahara, Rept. Natl. Food Res. Inst., 42, 14 (1983).

8) K. Lorenz and G. Hinze, J. Agric. Food Chem., 24, 911 (1976).

9) G. K. Adkins and C. T. Greenwood, Starch/Stärke, 18, 213 (1966).

10) S. Fujimoto, T. Nagahama and M. Kanie, Nippon Nōgeikagaku Kaishi, 46, 577 (1972).

11) Y. Ikawa, D. V. Glover, Y. Sugimoto and H. Fuwa, Starch/Stärke, 33, 9 (1981).

12) N. Inouchi, D. V. Glover, Y. Sugimoto and H. Fuwa, Starch/Stärke, 36, 8 (1984).

13) Y. Ikawa, Y. Chikazawa, S. Sakamoto and H. Fuwa, J. Jpn. Soc. Starch Sci, 31, 139 (1984).

14) Y. Ikawa, M. Y. Kang, M. Asaoka, S. Sakamoto and H. Fuwa, J. Jpn. Soc. Starch Sci., 30, 5 (1983).

15) M. Asaoka, K. Okuno, Y. Sugimoto and H. Fuwa, Agric. Biol. Chem., 49, 1973 (1985).

16) M. Asaoka, K. Okuno, Y. Sugimoto, M. Yano, T Omura and H. Fuwa, Starch/Stärte, 37, 364 (1985).

17) M. Asaoka, K. Okuno, Y. Sugimoto, M. Yano, T. Omura and H. Fuwa, Starch/Stärke, 38, 114 (1986). 